\title{
SOME ANALYTICAL PROPERTIES OF SOLUTIONS OF DIFFERENTIAL EQUATIONS OF NONINTEGER ORDER
}

\author{
S. M. MOMANI, S. B. HADID, and Z. M. ALAWENH
}

Received 25 February 2003

\begin{abstract}
The analytical properties of solutions of the nonlinear differential equations $x^{(\alpha)}(t)=$ $f(t, x), \alpha \in \mathbb{R}, 0<\alpha \leq 1$ of noninteger order have been investigated. We obtained two results concerning the frame curves of solutions. Moreover, we proved a result on differential inequality with fractional derivatives.
\end{abstract}

2000 Mathematics Subject Classification: 26A33.

1. Introduction. The problem of existence and uniqueness of solutions of the nonhomogeneous differential equations with fractional derivatives

$$
x^{(\alpha)}(t)=f(t, x), \quad \alpha \in \mathbb{R}, 0<\alpha \leq 1,
$$

with the initial condition

$$
x^{(\alpha-1)}\left(t_{0}\right)=x_{0}
$$

where $\mathbb{R}$ is the set of real numbers, $t \in I=[0, \infty)$, and $f$ is a real-valued function on $D=I \times \mathbb{R}^{n}$ into $\mathbb{R}^{n}$ where $\mathbb{R}^{n}$ denotes the real $n$-dimensional Euclidean space, and $x_{0} \in \mathbb{R}^{n}$, has been investigated by some authors (see $[1,2,6,9]$ ).

In recent years, interest has increased concerning the numerical treatment of fractional differential equations (see [4, 5, 11, 12]). On the other hand, differential inequalities and comparison theorems with the unique solution are very important for the numerical solution of differential equations (see [8] for fractional differential equations, and [10] for ordinary differential equations).

In this note, we will obtain a differential inequality result of (1.1) and (1.2), our result is more general than that in [8]. Also, we obtain two results concerning frame curves, the lower and upper frame curves of the solutions of (1.1) and (1.2); these two results are extensions to those in [10] for ordinary differential equations.

We will use the definitions and terminology used in Barrett [3] and Al-Bassam [2].

It is worth mentioning that it was shown by Hadid and Alshamani [7] that the solutions of (1.1) and (1.2) satisfy the integral equation

$$
x(t)=\frac{x_{0}\left(t-t_{0}\right)^{\alpha-1}}{\Gamma(\alpha)}+\frac{1}{\Gamma(\alpha)} \int_{t_{0}}^{t}(t-s)^{\alpha-1} f(s, x(s)) d s,
$$


where $0<t_{0}<t \leq t_{0}+a$, provided that the integral exists in the Lebesque sense, where $\Gamma$ is the Gamma function.

2. The main theorems. In this section, we will prove the main theorems.

THEOREM 2.1. Let $f(t, x)$ be a continuous function on the region

$$
\mathbb{R}(a, b): 0<t_{0}<t \leq t_{0}+a, \quad\left|x-x_{0}\left(t-t_{0}\right)^{\alpha-1}\right| \leq b .
$$

Suppose $x_{1}(t)$ is a solution of the differential inequality

$$
x^{(\alpha)}(t) \leq f\left(t, x_{1}(t)\right) \quad \text { on }\left(t_{0}, t_{0}+a\right],
$$

then there exists a solution $x_{2}(t)$ of the differential inequality

$$
x_{2}^{(\alpha)}(t) \geq f\left(t, x_{2}(t)\right) \quad \text { on }\left(t_{0}, t_{0}+a\right], \quad x_{1}^{(\alpha-1)}\left(t_{0}\right) \leq x_{2}^{(\alpha-1)}\left(t_{0}\right)
$$

such that on this interval, $x_{1}(t) \leq x_{2}(t)$.

Proof. Let $\psi\left(t, x_{2}\right)=f\left(t, \max \left(x_{2}, x_{1}(t)\right)\right)$. Obviously, $\psi$ is a continuous function on $\mathbb{R}$.

First we will prove the inequality

$$
x_{1}(t) \leq w(t) \text { for } t \in\left[t_{0}, t_{0}+a\right],
$$

where $w(t)$ satisfies the differential inequality

$$
w^{(\alpha)}(t) \geq \psi(t, w(t)), \quad w^{(\alpha-1)}\left(t_{0}\right)=x_{2}^{(\alpha-1)}\left(t_{0}\right) .
$$

Suppose that this is not true, that is, that for some value $\tau, w(\tau)<x_{1}(\tau)$. Let $\tau_{0}$ be the lower bound of numbers $s$ for which we have $w(t)<x_{1}(t)$ for $s \leq t \leq \tau$. Then $w\left(\tau_{0}\right)=x_{1}\left(\tau_{0}\right)$ and $w(t)<x_{1}(t)$ for $\tau_{0}<t<\tau$.

Therefore, we get

$$
\psi(t, w(t))=f\left(t, x_{1}(t)\right) \quad \text { on } t \in\left[\tau_{0}, \tau\right] .
$$

Using inequality (2.2) and (1.3), it follows that

$$
\begin{aligned}
x_{1}(\tau) & \leq \frac{x_{1}\left(\tau_{0}\right)\left(\tau-\tau_{0}\right)^{\alpha-1}}{\Gamma(\alpha)}+\frac{1}{\Gamma(\alpha)} \int_{\tau_{0}}^{\tau}(\tau-s)^{\alpha-1} f\left(s, x_{1}(s)\right) d s \\
& =\frac{w\left(\tau_{0}\right)\left(\tau-\tau_{0}\right)^{\alpha-1}}{\Gamma(\alpha)}+\frac{1}{\Gamma(\alpha)} \int_{\tau_{0}}^{\tau}(\tau-s)^{\alpha-1} \psi(s, w(s)) d s,
\end{aligned}
$$

and from (2.5) and (2.7), we get $x_{1}(\tau) \leq w(\tau)$, which is in contradiction with our supposition. This proves inequality (2.4).

But now because (2.4) implies that a solution of inequality (2.5) is also a solution of inequality (2.3), we see that the result follows from (2.4).

REMARK 2.2. The above theorem means that the solution $x_{1}(t)$ is dominated by the solution $x_{2}(t)$. Moreover, if $x_{2}(t)$ is a bounded solution, then so is $x_{1}(t)$. 
THEOREM 2.3. Let $\phi(t, y), f(t, y)$, and $F(t, y)$ be continuous functions on the region

$$
\mathbb{R}_{1}(a, b): 0<t_{0}<t \leq t_{0}+a, \quad\left|y-y_{0}\left(t-t_{0}\right)^{\alpha-1}\right| \leq b
$$

and satisfy

$$
\phi(t, y) \leq f(t, y) \leq F(t, y)
$$

Further let $x=x(t), y=y(t)$, and $X=X(t)$ be solutions of the differential equations

$$
x^{(\alpha)}(t)=\phi(t, x), \quad y^{(\alpha)}(t)=f(t, y), \quad X^{(\alpha)}(t)=F(t, X),
$$

which pass through the point $\left(t_{0}, y_{0}\left(t-t_{0}\right)^{\alpha-1}\right)$, defined on $\left[t_{0}, t_{0}+a\right]$, and which lie between $y_{0}\left(t-t_{0}\right)^{\alpha-1}-b$ and $y_{0}\left(t-t_{0}\right)^{\alpha-1}+b$.

If the function $f(t, y)$ satisfies the Lipschitz condition in the second parameter on $\mathbb{R}_{1}(a, b)$ :

$$
\left|f\left(t, y_{1}\right)-f\left(t, y_{2}\right)\right| \leq L\left|y_{1}-y_{2}\right|
$$

for some positive constant $L$, then

$$
x(t) \leq y(t) \leq X(t) .
$$

Proof. It is clear from Theorem 2.1 and equations (2.9) and (2.10) that the following inequalities:

$$
X^{(\alpha)}(t)-f(t, X) \geq 0, \quad x^{(\alpha)}(t)-f(t, x) \leq 0, \quad x(t) \leq y(t) \leq X(t),
$$

are satisfied if

$$
X=y_{0}\left(t-t_{0}\right)^{\alpha-1}+Y, \quad x=y_{0}\left(t-t_{0}\right)^{\alpha-1}-Y,
$$

where

$$
Y=\frac{1}{\Gamma(\alpha)} \int_{t_{0}}^{t}(t-s)^{\alpha-1}\left|f\left(s, y_{0}\right)\right| d s \leq \frac{M}{\alpha \Gamma(\alpha)}\left(t-t_{0}\right)^{\alpha},
$$

and $M$ is a positive real constant such that $|f(s, y)| \leq M$.

Hence, the theorem is proved.

REMARK 2.4. The functions $X(t)$ and $x(t)$ are called "frame curves."

THEOREM 2.5. Let the functions $f(t, y), F(t, y), y(t)$, and $X(t)$ be defined as in Theorem 2.3. Set $h(t)=X^{(\alpha)}(t)-f(t, X(t))$, then the function

$$
X_{1}(t)=X(t)-\frac{1}{\Gamma(\alpha)} \int_{t_{0}}^{t}(t-s)^{\alpha-1} e^{-L(t-s)} h(s) d s,
$$

where $L$ the Lipschitz constant for the function $f(t, y)$ is an upper frame curve on the interval $\left[t_{0}, t_{0}+a\right]$, and on that interval there exist the inequalities

$$
y(t) \leq X_{1}(t) \leq X(t) .
$$


Proof. The inequality $X_{1}(t) \leq X(t)$ is obvious. On the other hand, as in [10], we have

$$
\begin{aligned}
X^{(\alpha)}(t)-f\left(t, X_{1}(t)\right) \\
=X^{(\alpha)}(t)-h(t)+\frac{L}{\Gamma(\alpha)} \int_{t_{0}}^{t}(t-s)^{\alpha-1} e^{-L(t-s)} h(s) d s-f\left(t, X_{1}(t)\right) \\
=f\left(t, X_{1}(t)\right)-f(t, X(t))+L\left[X(t)-X_{1}(t)\right] \geq 0 .
\end{aligned}
$$

Thus $y(t) \leq X_{1}(t)$.

REMARK 2.6. By using the same above procedure, we can show that if $x(t)$ a lower frame and if we set

$$
h_{1}(t)=x^{(\alpha)}(t)-f(t, x(t)),
$$

then

$$
x_{1}(t)=x(t)-\frac{1}{\Gamma(\alpha)} \int_{t_{0}}^{t}(t-s)^{\alpha-1} e^{-L(t-s)} h_{1}(s) d s
$$

is also a lower frame curve and we have

$$
y(t) \leq x_{1}(t) \leq y(t)
$$

ACKNOWLEDGMENTS. The authors are pleased to express thanks to the United Arab Emirates University for its financial support. The first author is on a leave from Mutah University, Jordan.

\section{REFERENCES}

[1] A. Z. Al-Abedeen and H. L. Arora, A global existence and uniqueness theorem for ordinary differential equations of generalized order, Canad. Math. Bull. 21 (1978), no. 3, 267271.

[2] M. A. Al-Bassam, Some existence theorems on differential equations of generalized order, J. reine angew. Math. 218 (1965), 70-78.

[3] J. H. Barrett, Differential equations of non-integer order, Canadian J. Math. 6 (1954), 529541.

[4] L. Blank, Numerical treatment of differential equations of fractional order, MCCM Numerical Analysis Report 287, Manchester Centre for Computational Mathematics, Manchester, UK, 1996.

[5] K. Diethelm, An algorithm for the numerical solution of differential equations of fractional order, Electron. Trans. Numer. Anal. 5 (1997), 1-6.

[6] S. B. Hadid, Local and global existence theorems on differential equations of non-integer order, J. Fract. Calc. 7 (1995), 101-105.

[7] S. B. Hadid and J. G. Alshamani, Liapunov stability of differential equations of noninteger order, Arab J. Math. 7 (1986), no. 1-2, 5-17.

[8] S. B. Hadid, B. Masaedeh, and S. Momani, On the existence of maximal and minimal solutions of differential equations of non-integer order, J. Fract. Calc. 9 (1996), 41-44.

[9] S. B. Hadid, A. A. Ta'ani, and S. M. Momani, Some existence theorems on differential equations of generalized order through a fixed-point theorem, J. Fract. Calc. 9 (1996), 45-49. 
[10] D. S. Mitrinović, J. E. Pečarić, and A. M. Fink, Inequalities Involving Functions and Their Integrals and Derivatives, Mathematics and Its Applications (East European Series), vol. 53, Kluwer Academic Publishers Group, Dordrecht, 1991.

[11] S. Momani and S. B. Hadid, An algorithm for numerical solutions of fractional order differential equations, J. Fract. Calc. 15 (1999), 61-66.

[12] I. Podlubny, Numerical solution of ordinary fractional differential equations by the fractional difference method, Advances in Difference Equations (Veszprém, 1995), Gordon and Breach, Amsterdam, 1997, pp. 507-515.

S. M. Momani: Department of Mathematics and Computer Science, Faculty of Science, United Arab Emirates University, P.O. Box 17551, Al-Ain, UAE

E-mail address: shahermm@yahoo.com

S. B. Hadid: Department of Mathematics and Basic Science, Faculty of Science, Ajman Center, Ajman University of Science and Technology, P.O. Box 17550, Al-Ain, UAE

E-mail address: sbhadid@yahoo.com

Z. M. Alawenh: Department of Mathematics, Faculty of Science, University of Qater, Qater E-mail address: zaka 1 awneh@yahoo.com 


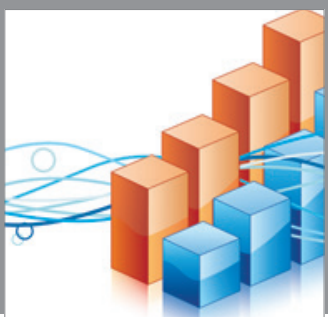

Advances in

Operations Research

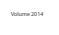



\section{The Scientific} World Journal


International Journal of

Mathematics and

Mathematical

Sciences
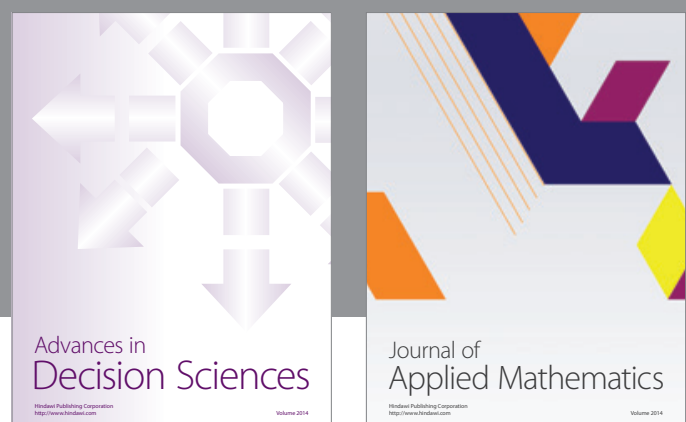

Journal of

Applied Mathematics
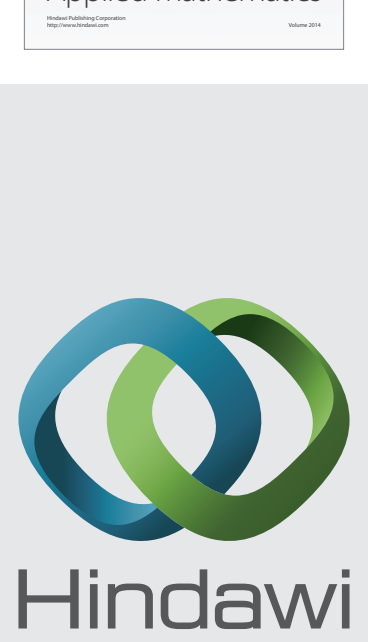

Submit your manuscripts at http://www.hindawi.com
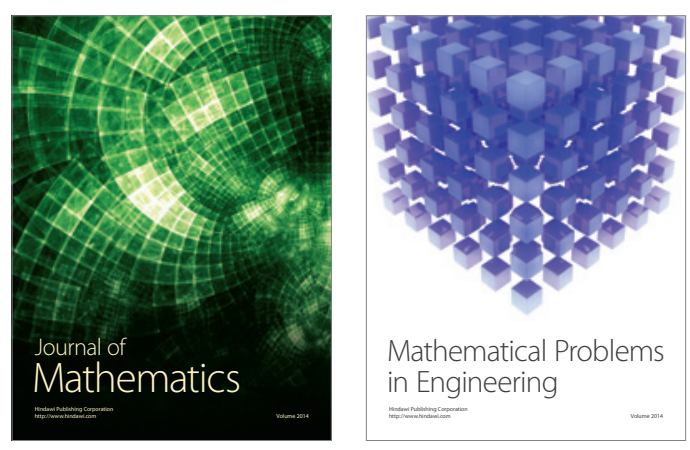

Mathematical Problems in Engineering


Journal of

Function Spaces
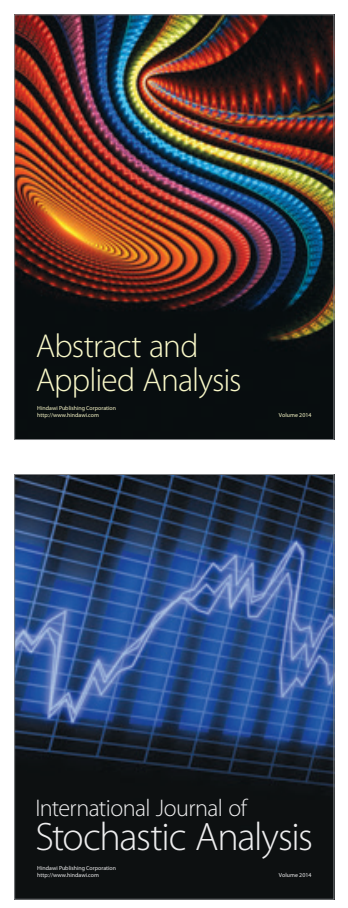

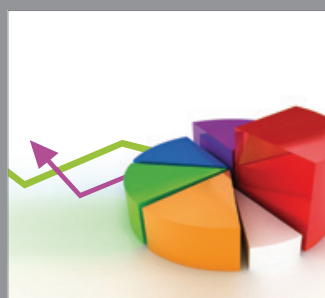

ournal of

Probability and Statistics

Promensencen
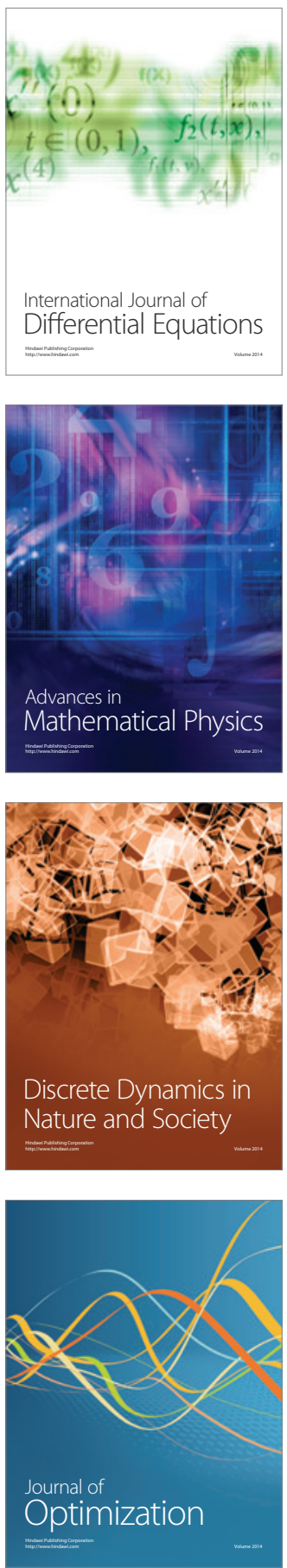